\title{
As desigualdades na distribuição dos óbitos no município de Salvador - 1980.
}

* Departamento de Medicina Pre. ventiva da Faculdade de Medicina da UFBA.

* * Departamento de Medicina Preventiva da Faculdade de Medicina da UFBA e Secretaria de Saúde do Estado da Bahia.
Recebido para publicação em 25.07.86.

\author{
Jairnilson Silva Paim* \\ Maria da Conceição Nascimento Costa *
}

O presente estudo teve como objetivo descrever a distribuição da mortalidade do Municipio de Salvador em 1980 , segundo as diferentes zonas da cidade, utilizando-se do coeficiente de mortalidade geral, da razão da mortalidade proporcional, da curva de mortalidade proporcional e do indicador quantificado de Guedes \& Guedes.

Utilizou-se como fonte de dados as Declarações de Obitos disponiveis na Secretaria de Saúde do Estado da Bahia referentes aos residentes de Salvador no ano de 1980, agrupados segundo zonas de informação definidas pela CONDER, bem como indicadores sócio-econômicos cujos dados foram coletados em diferentes órgãos públicos. Aplicaram-se testes estatisticos de correlação entre as razões de mortalidade proporcional e os indicadores sócio-econômicos selecionados.

Verificou-se uma expressiva variaçđo dos indicadores entre os diferentes bairros da cidade, mesmo considerando-se o uso de indicador com reconhecido baixo poder discriminatório como o coeficiente de mortalidade geral. Quanto aos indices de Swaroop-Uemura e de Moraes e ao sistema de pontuação de Guedes e Guedes evidenciaram flagrantes desigualdades na distribuição das mortes entre os diferentes bairros de Salvador. Os elevados indices de correlação encontrados entre a razão da mortalidade proporcional e a renda, a disponibilidade de água e a aglomeração reforçam a idéia de que na base dessa desigualdade encontra-se a estrutura economica geradora de iniqüidades.

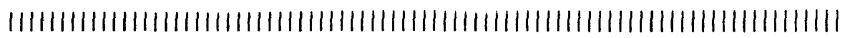

\section{INTRODUÇÃO}

A avaliação das condições de saúde de uma população é realizada através de indicadores, constituídos, usualmente, a partir de informações rotineiramente coletadas por órgãos oficiais. Embora a maioria dessas informações expresse, na realidade, condiçoes que se afastam do estado de saúde, como a doença e a morte, o recurso aos indicadores baseados na morbidade e na mortalidade é imprescindível no Cadernos de Saúde Pública, R.J., 2 (3): 312-333, jul/set, 1986. 
campo da Saúde Pública ${ }^{6}$. Esta opção se justifica não só em função da maior disponibilidade dessas informações, mas também pela facilidade de se proceder comparaçoes internacionais, interregionais ou mesmo entre diferentes localidades de uma mesma cidade.

Muitos desses indicadores de saúde utilizados no Brasil são coeficientes de mortalidade ou valores de mortalidade proporcional por idade ou por grupos específicos de causas de óbito ${ }^{11}$.

Recentemente, Novo et alii ${ }^{9}$ propuseram um indicador de nível de saúde abrangente contemplando vários indicadores usuais tais como o coeficiente de mortalidade geral, indicador quantificado de Guedes, esperança de vida ao nascer, coeficiente de natalidade, coeficiente de mortalidade infantil e coeficiente de mortalidade por doenças transmissíveis. $\mathrm{O}$ emprego desse indicador abrangente teria a vantagem de evitar as discrepâncias entre as posições relativas que uma localidade ocupa nas diferentes ordenações estabelecidas pelos distintos indicadores utilizados isoladamente. Todavia, enfrenta-se, ainda, com a limitação de uso nas localidades em que nem todos eles estejam disponíveis.

No caso do Município de Salvador, as estatísticas oficiais apontam para um decréscimo dos indicadores baseados na mortalidade nos últimos anos, muito embora indicadores como os coeficientes de natalidade, de mortalidade infantil, e de mortalidade materna não sejam disponíveis para a série histórica em virtude do desconhecimento do número real de nascidos vivos. Além disso, não expressam a variação dos níveis de saúde entre os diferentes bairros porquanto baseiam-se em dados agregados para o município como um todo.

Considerando-se a diversidade das condições de vida a que está sujeita a população de Salvador ${ }^{10,13}$ e admitindose que o local de residência expresse, de forma aproximada, o nível sócio-econômico dos segmentos sociais ${ }^{7}$, seria justificada a realização de um estudo que examinasse a distribuição da ocorrência da totalidade de óbitos dentro do espaço urbano. Este tipo de estudo não obstante as suas limitações, mostrou-se com certa utilidade na análise de mortalidade infantil proporcional ${ }^{*}$ e da mortalidade do grupo etário de 1 a 14 anos $^{3}$.

Nessa perspectiva, a presente investigação visa descrever a distribuição da mortalidade no Município de Salvador em 1980 , segundo as diferentes zonas da cidade, utilizando-se do coeficiente de mortalidade geral, da razão da mortalidade proporcional e do indicador quantificado de Guedes e Guedes. 


\section{MATERIAL E MÉTODOS}

Utilizou-se como fonte de dados as Declarações de Óbitos arquivadas no Centro de Informações de Saúde (CIS) da Secretaria de Saude do Estado da Bahia e referentes aos residentes de Salvador no ano de 1980. Foram, portanto, colhidos das Declaraçбes os dados dos itens 9, 13 e 14, correspondentes à idade, residência habitual e município de residência do falecido.

As Declarações foram agrupadas de acordo com os respectivos bairros da residência, considerando-se as zonas de informação (ZI) estabelecidas para o Município de Salvador. Estas correspondem a uma divisão da cidade realizada pela Companhia de Desenvolvimento da Região Metropolitana (CONDER), tomando como referência critérios de unidades físico-urbanísticos, geográficos, além de elementos administrativos e de planejamento ${ }^{2}$. Do mesmo modo, após o levantamento desses óbitos, procedeu-se a sua distrubuição segundo os grupos etários para a construção dos diferentes indicadores.

Nessa ocasião, alguns problemas foram detectados entre os quais o preenchimento incorreto das Declarações de Óbito e as divergências entre o número das Declarações arquivadas no CIS e o publicado oficialmente pelo IBGE ${ }^{1}$, já comentados em outra oportunidade. Embora tenham sido indentificadas 11.887 declarações de óbitos (D.O.), a má qualidade do seu preenchimento impôs a exclusão do estudo de parte dessas declarações.

Os níveis de saúde da população de Salvador foram medidos através dos seguintes indicadores:

a) coeficientes de mortalidade geral (CMG);

b) razão de mortalidade proporcional (RMP) ou Índice de Swaroop-Uemura;

c) curva de mortalidade proporcional (CMP) ou indicador Moraes;

d) Indicador Quantificado de Guedes e Guedes.

O coeticiente de mortalidade geral é calculado dividindose o total de óbitos ocorridos em todas as idades pela população de uma dada área e multiplicando-se por mil. Embora utilize como base referencial uma população exposta ao risco de morrer ${ }^{12}$, é um indicador cuja magnitude é afetada pela composição da população por idade ${ }^{5}$. É fácil de calcular, mas tem baixo poder discriminatório ${ }^{5}$. No presente estudo, - CMG foi calculado inicialmente para cada zona de informação (ZI) da cidade com base em dados da população estimados pela CONDER. Excluíram-se desses cálculos 499 Declarações de óbitos sendo 366 por apresentarem endereços incompletos que não permitiram a classificação dos óbitos 
por ZI, e 83 por pertencerem a ZI com menos de 1000 habitantes e que mantendo critérios de estudos anteriores ${ }^{1,3}$ foram, portanto, abandonados. Estes óbitos correspondiam as ZI do Acesso Norte do Centro Administrativo, de Piatã/ Patamares, Praias do Flamengo, São Bartolomeu e a zona 72 limite com a Usiba.

A razão da mortalidade proporcional corresponde a percentagem de óbitos no grupo de 50 anos e mais em relação ao número total de óbitos. Assim, o índice de Swaroop e Uemura dá uma idéia de longevidade da população na medida em que se aproxima de $100 \%$, caso a maioria das pessoas sobrevivesse até os 50 anos. Segundo Jordan Filho et alii " "trata-se de um indicador simples, fácil de calcular, robusto em relação aos dados fornecidos pelo atestado de óbito, podendo ser calculado mesmo nas regiões em que ocorram muitos óbitos sem assistência médica, já que não leva em conta a causa da morte e parece ter um bom poder discriminatório. A RMP foi calculada para 11.318 declarações de óbitos do ano de 1980 , por terem sido excluídas 569 D.O., em virtude de faltarem informações completas do endereço e/ou idade do falecido e 15 D.O. das zonas 36 (19 BC), 46 (Piatã/Patamares), 67 (São Bartolomeu), 72 (Limite com a Usiba) e 74 (Ilhas) onde em cada uma delas ocorreram menos de sete óbitos.

Calculados os CMG e as RMP para cada ZI da Cidade, os indicadores foram dispostos em ordem crescente no primeiro caso e decrescente no segundo. Para ambos os indicadores estabeleceram-se 4 agrupamentos de zonas de informação em função de seus valores. O primeiro quartil correspondia a uma mortalidade "baixa", o segundo "intermediária", o terceiro "elevada" e o último "muito elevada".

Para cada um dos agrupamentos formados a partir do ordenamento dos valores de RMP foi construida a respectiva curva de mortalidade proporcional (CMP) calculando-se a percentagem de óbitos dos seguintes grupos etários: menos de 1 ano, 1 a 4, 5 a 19, 20 a 49 e 50 anos e mais. Segundo Moraes ${ }^{8}$ podem existir os seguintes tipos de curvas:

Tipo I - Nível de saúde muito baixo - coletividades com péssimas condiçбes de saúde e com mortalidade elevada nos menores de 1 ano e na faixa etária de 20 a 49 anos. Curva com aspecto irregular.

Tipo II - Nível de saůde baixo - coletividade com condições de saúde um pouco melhores, havendo uma redução dos valores de mortali. dade proporcional em certos grupos etários e aumento relativo em outros como os de menos de 1 ano. 
Tipo III - Nível de saúde regular - coletividade em que a melhora das condiçóes de saúde já permite mostrar uma concentração de óbitos no grupo de 50 anos e mais, passando a curva da forma de $\mathrm{J}$ invertido para $\mathrm{J}$ normal.

Tipo IV - Nivel de saúde elevado - pequena contribuição dos grupos de menos de 20 anos para o total de óbitos e concentração no grupo de 50 anos e mais. A curva apresenta-se com forma de $\mathrm{J}$ normal.

Foi também empregado o indicador quantificado de Gue. des visando a quantificar o Indicador de Moraes para o Município de Salvador e especialmente para os diferentes agrupamentos de ZI constituídos, em função da RMP. Esta quantificação gera um indicador, cujas cifras variam de valores negativos até o máximo teórico de +50 considerando-se a seguinte ponderação para cada grupo etário:

$$
\begin{array}{cc}
<1 \text { ano } & -4 \\
1-4 & -2 \\
5-19 & -1 \\
20-49 & -3 \\
50 \text { ou mais } & +5
\end{array}
$$

Após a soma algébrica dos valores encontrados divide-se o resultado por dez. Obtém-se, desse modo, uma aferição do grupo de discriminação cuja passagem de valores negativos para positivos expressa uma progressiva melhoria dos níveis de saúde.

Finalmente, as razōes de mortalidade proporcional (RMP) foram analisadas à luz dos indicadores sócioeconômicos abaixo relacionados, aplicando-se o teste estatístico de correlação para o cálculo do coeficiente de Spearman, aceitando-se o nível de significância estatística menor de 0.05 para $n \cdot 2$ graus de liberdade.

Nessa perspectiva, foram utilizados os seguintes indicadores sócio-econômicos:

a) Proporção de familias de baixa renda - percentual de familia com rendimentos de 0 a 5 salários mínimos.

b) Disponibilidade de água per capita : litros de água consumidos por habitantes por dia.

c) Aglomeração - número de habitantes por domiculio.

d) Disponibilidade de médicos de Centros e Postos de Saúde: número de profissionais médicos existentes nos Centros e Postos de Saúde para cada 10.000 habitantes. 
Tais dados foram fornecidos, respectivamente, pelo Órgão Central de Planejamento (OCEPLAN), Empresa Bahiana de Saneamento (EMBASA), pela Companhia de Desenvolvimento da Região Metropolitana de Salvador (CONDER) e pelas 1a Diretoria Regional de Saúde e Secretaria Municipal de Saúde.

\section{RESULTADOS}

O Município de Salvador apresentou no ano de 1980 um coeficiente de mortalidade geral de 7,9/1000 habitantes, uma razão de mortalidade proporcional de $41,2 \%$ e uma curva de mortalidade proporcional (Gráfico 1) indicadora de um "regular" estado sanitário.

\section{GRÁFICO 1}

MORTALIDADE PROPORCIONAL, SEGUNDO A FAIXA ETÁRIA MUNICIPIO DE SALVADOR - 1980

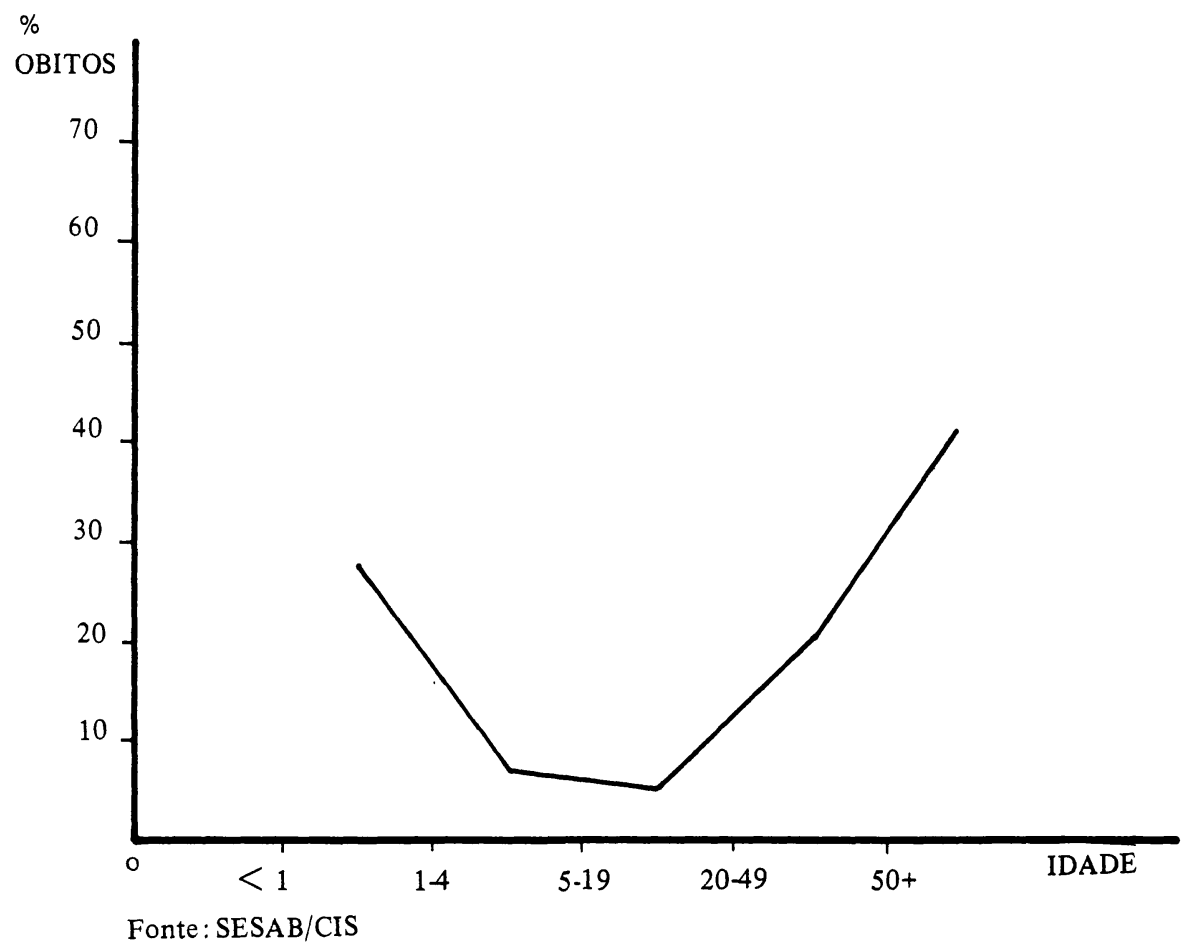

No Anexo 1, constam os indicadores de saúde calculados para cada zona de informação (ZI) que permitiram o orde. namento das ZI de modo crescente no caso do coeficiente de mortalidade geral (CMG) e em ordem decrescente no que tange a razão da mortalidade proporcional (RMP). 
PESQUISA

\section{ANEXO 1}

Distribuição da população, do número de óbitos e mortalidade proporcional por faixa etária, no ut:t: de óbitos e coeficiente geral de mortalidade e de alguns indicadores sócio-econômicos segundo zonas de informação - municipio de Salvador - Bahia - 1980

Óbitos por faixa etária (anos)

Zona de informação

No Nome

$\begin{array}{lcccccc}\text { População } & 1 & 1-4 & 5-19 & 20-49 & 50 \\ & \text { No. MP } & \text { No. MP } & \text { No. MP } & \text { No } & \text { MP } & \text { No }\end{array}$

\begin{tabular}{|c|c|c|c|c|c|c|c|c|c|c|c|}
\hline 01 & Barra & 30.744 & 20 & 10,2 & 4 & 2,0 & 8 & 4,1 & 37 & 18,9 & 12764,8 \\
\hline 02 & Jardim Apipema & 12.966 & 13 & 36,1 & - & - & 1 & 2,8 & 5 & 13,9 & 1747,2 \\
\hline 03 & Ondina & 5.430 & 8 & 25,8 & 1 & 3,2 & - & - & 7 & 22,6 & 1548,4 \\
\hline $4 / 5$ & Rio Vermelho & 19.883 & 47 & 23,7 & 12 & 6,1 & 14 & 7,1 & 32 & 16,2 & 9346,9 \\
\hline 06 & Amaralina & 28.753 & 16 & 18,2 & 5 & 5,7 & 6 & 6,8 & 11 & 12,5 & $50 \quad 56,8$ \\
\hline 07 & Nord. Amaralina & 39.016 & 87 & 30,1 & 23 & 7,9 & 19 & 6,6 & 50 & 17,3 & 11038,1 \\
\hline 08 & Pituba & 24.873 & 27 & 17,1 & 7 & 4,4 & 5 & 3,2 & 29 & 18,4 & 9056,9 \\
\hline 09 & Campo Grande/Vitória & 9.070 & 2 & 3,9 & - & - & 3 & 5,9 & 12 & 23,5 & 3466,7 \\
\hline 10 & Graça & 13.583 & 8 & 8,2 & 2 & 2,1 & 3 & 3,1 & 15 & 15,5 & 6971,5 \\
\hline \multirow[t]{2}{*}{11} & Alto das Pombas/Federação/ & & & & & & & & & & \\
\hline & Eng? Velho Federação & 59.693 & 91 & 21,0 & 18 & 4,1 & 12 & 2,8 & 96 & 22,1 & 21750,0 \\
\hline 13 & Horto Florestal & 9.107 & 7 & 30,4 & 2 & 8,7 & 1 & 4,4 & 1 & 4,4 & 1252,1 \\
\hline 14 & Canela & 8.536 & 14 & 6,4 & 1 & 2,1 & 2 & 4,3 & 5 & 10,6 & 3676,6 \\
\hline 15 & Centro Histórico & 21.854 & 32 & 18,0 & 5 & 2,8 & 7 & 3,9 & 39 & 21,9 & $95 \quad 53,4$ \\
\hline 16 & Garcia & 12,890 & 14 & 14,1 & 3 & 3,1 & 1 & 1,0 & 9 & 9,1 & 7272,7 \\
\hline 17 & te Nova & 15 & 14 & 14,0 & 2 & 2,0 & 7 & 7,0 & 20 & 20,0 & $57 \quad 57,0$ \\
\hline 18 & Brotas & 32. & 44 & 21,8 & 5 & 2,5 & 12 & 5,9 & 35 & 17,3 & 10652,5 \\
\hline 19 & Act & 0 & 11 & 19,0 & 4 & 6,9 & 3 & 5,2 & 9 & 15,4 & $31 \quad 53,5$ \\
\hline 20 & Brot & 6 & 77 & 19,6 & 23 & 5,9 & 20 & 5,1 & 69 & 17,6 & 203 \\
\hline 21 & . da Luz/Itaigara & 2 & 2 & 18,2 & 1 & 9,1 & 1 & 9,1 & 3 & 27,2 & ,4 \\
\hline 22 & Sti & 13 & 9 & 1 & 6 & 5 & 2 & 5,1 & 7 & 18,0 & 15 \\
\hline 23 & ontes & 8 & 5 & 16,1 & 1 & 3,3 & 8 & 25,8 & 5 & 16,1 & 1238,7 \\
\hline 24 & nile/B. Sapateiro & 5 & 26 & 16,9 & 6 & 3,9 & 2 & 1,3 & 35 & 22,7 & 8555,2 \\
\hline 25 & /Saúde & 4 & 28 & 10,7 & 4 & 1,5 & 8 & 3,1 & 44 & 16,9 & $177 \quad 67,8$ \\
\hline 26 & Mata & 12.561 & 9 & 7,6 & 3 & 2,5 & 4 & 3,4 & 21 & 17,8 & 8168,7 \\
\hline 27 & Cosme far & 34.207 & 82 & 30,7 & 20 & 7,5 & 14 & 5,2 & 57 & 21,4 & 9435,2 \\
\hline 28 & Luis Anselmo/Vila Laura & 15.016 & 10 & 20,0 & 1 & 2,0 & 3 & 6,0 & 11 & 22,0 & 2550,0 \\
\hline 29 & Cabula & 16.437 & 124 & 40,1 & 35 & 11,3 & 16 & 5,2 & 56 & 18,1 & $78 \quad 25,2$ \\
\hline 30 & Pernambu & 31.321 & 123 & 39,8 & 32 & 10,3 & 12 & 3,9 & 71 & 23,0 & 7123,0 \\
\hline 31 & Boc & 29.211 & 90 & 30,1 & 31 & 11,4 & 18 & 6,6 & 48 & 17,7 & $85 \quad 31,2$ \\
\hline 32 & Barbalho/Lapinha & 18.412 & 35 & 20,5 & 6 & 3,5 & 6 & 3,5 & 40 & 23,4 & 8449,1 \\
\hline 33 & Caixa D’água & 29.699 & 16 & 15,7 & 2 & 2,0 & 3 & 2,9 & 16 & 15,7 & 6563,7 \\
\hline 34 & Quintas/Cidade Nova & 36.451 & 68 & 22,1 & 15 & 4,9 & 16 & 5,2 & 51 & 16,5 & $158 \quad 51,3$ \\
\hline $35^{*}$ & Acesso Norte & 718 & 8 & 24,2 & 3 & 9,1 & 3 & 9,1 & 8 & 2,42 & 1133,4 \\
\hline $36 *$ & $19 \mathrm{BC}$ & 5.190 & 1 & 33,3 & - & - & 1 & 33,3 & 1 & 33,4 & - \\
\hline 37 & Pituaçu & 6.782 & 6 & 28,6 & 2 & 9,5 & - & - & 8 & 38,1 & 523,8 \\
\hline 38 & Calçada/mares/Roma & 23.107 & 26 & 9,9 & 9 & 3,4 & 9 & 3,4 & 35 & 13,4 & $183 \quad 69,9$ \\
\hline \multicolumn{12}{|c|}{$39 /$} \\
\hline 40 & Lit & 33 & 167 & 24 & 28 & 4 & 32 & 4,6 & 105 & 15,2 & 36052,0 \\
\hline 41 & IA & 29.342 & 53 & 31,9 & 17 & 10,3 & 11 & 6,6 & 37 & 22,3 & $48 \quad 28,9$ \\
\hline 42 & Fazer & & 88 & 30,6 & 19 & 6,2 & 18 & 6,6 & 64 & 22,2 & 9034,4 \\
\hline , & S. Gonçalo Retiro & 12.227 & 57 & 41,6 & 18 & 12,4 & 3 & 2,9 & 25 & 18,3 & $34 \quad 24,8$ \\
\hline
\end{tabular}




\begin{tabular}{|c|c|c|c|c|c|c|c|}
\hline \multicolumn{2}{|c|}{ Total 0-50 } & \multirow[t]{2}{*}{$\begin{array}{l}\text { NO de habitantes } \\
\text { por domicílio }\end{array}$} & \multirow{2}{*}{$\begin{array}{l}\text { Volume de água } \\
\text { (litros/dia) } \\
\text { consumido por } \\
\text { habitante/dia }\end{array}$} & \multirow{2}{*}{$\begin{array}{l}\text { Percentagem de } \\
\text { Habitantes com } \\
\text { renda na faixa } \\
\text { "C" }\end{array}$} & \multirow{2}{*}{$\begin{array}{l}\text { No de médicos } \\
\text { de centros e } \\
\text { postos de saúde } \\
\text { por } 40.000 / \\
\text { habitantes }\end{array}$} & \multirow{2}{*}{$\begin{array}{c}\text { Total } \\
\text { de } \\
\text { Obitos } \\
\text { No }\end{array}$} & \multirow{2}{*}{$\begin{array}{c}(1) \\
\mathrm{CGM}^{(2)}\end{array}$} \\
\hline No & $\mathrm{MP}$ & & & & & & \\
\hline 196 & 100,0 & 3,6 & 136,6 & - & - & 199 & 6,47 \\
\hline 36 & 100,0 & 3,9 & 136,6 & 14,6 & - & 36 & 2,77 \\
\hline 31 & 100,0 & 4,4 & 136,6 & 49,6 & - & 31 & 5,70 \\
\hline 198 & 100,0 & 4,5 & 135,0 & 64,8 & 8,0 & 199 & 10,00 \\
\hline 88 & 100,0 & 7,0 & 133,3 & 84,3 & - & $89^{\circ}$ & 3,09 \\
\hline 289 & 100,0 & 13,8 & 133,3 & 100,0 & 9,5 & 295 & 7,56 \\
\hline 158 & 100,0 & 3,8 & 133,3 & 1,3 & - & 158 & 6,35 \\
\hline 51 & 100,0 & 4,0 & 136,6 & - & 2,2 & 51 & 5,62 \\
\hline 97 & 100,0 & 3,9 & 136,6 & - & - & 00 & 7,21 \\
\hline 434 & 100,0 & 7,2 & 136,6 & 76,3 & 2,0 & 440 & 7,37 \\
\hline 23 & 100,0 & 5,2 & 133,3 & 78,4 & - & 23 & 2,53 \\
\hline 47 & 100,0 & 3,9 & 136,6 & - & - & 47 & 5,51 \\
\hline 178 & 100,0 & 4,4 & 133,3 & 13,0 & - & 179 & 8,19 \\
\hline 99 & 100,0 & 4,9 & 136,6 & 67,9 & 3,9 & 100 & 7,76 \\
\hline 100 & 100,0 & 4,6 & 133,3 & 20,9 & 33,3 & 100 & 6,41 \\
\hline 202 & 100,0 & 6,2 & 100,0 & 78,4 & 0,6 & 204 & 6,31 \\
\hline 58 & 100,0 & 5,6 & 100,0 & 78,4 & 3 & 59 & 2,77 \\
\hline 392 & 100,0 & 5,5 & 100,0 & 78,4 & 2,3 & 298 & 15,35 \\
\hline 11 & 100,0 & 4,5 & 133,3 & 1,3 & - & 12 & 0,99 \\
\hline 39 & 100,0 & 3,8 & 73,3 & 36,0 & - & 40 & 2,87 \\
\hline 31 & 100,0 & 8,2 & 133,3 & 18,7 & - & 32 & 16,09 \\
\hline 154 & 100,0 & 5,6 & 133,3 & 18,7 & - & 158 & 10,71 \\
\hline 261 & 100,0 & 5,5 & 133,3 & 18,7 & 12,6 & 261 & 10,93 \\
\hline 118 & 100,0 & 4,7 & 100,0 & 36,8 & - & 120 & 9,55 \\
\hline 267 & 100,0 & 10,1 & 100,0 & 96,6 & 1,8 & 270 & 7,89 \\
\hline 50 & 100,0 & 5,0 & 100,0 & 36,8 & - & 52 & 3,46 \\
\hline 309 & 100,0 & 4,5 & 73,3 & 86,4 & 1,2 & 311 & 18,92 \\
\hline 309 & 100,0 & 12,1 & 73,3 & 86,4 & 4,2 & 315 & 10,60 \\
\hline 272 & 100,0 & 6.7 & 73,3 & 84,4 & 1,7 & 277 & 9,48 \\
\hline 171 & 100,0 & 5,6 & 70,0 & 86,0 & 1,6 & 180 & 9,78 \\
\hline 102 & 100,0 & 6,6 & 70,0 & 86,0 & - & 102 & 3,43 \\
\hline 308 & 100,0 & 7,8 & 70,0 & 86,0 & 0,8 & 309 & 8,48 \\
\hline 33 & 100,0 & $\ldots$ & $\ldots$ & $\ldots$ & - & 33 & 45,96 \\
\hline 3 & 100,0 & 3,7 & 73,3 & 99,8 & - & 5 & 0,96 \\
\hline 21 & 100,0 & 5,6 & 73,3 & 84,4 & - & 21 & 3,09 \\
\hline 262 & 100,0 & 6,0 & 70,0 & 46,8 & 26,8 & 264 & 11,43 \\
\hline $692^{\circ}$ & 100,0 & 8,5 & 70,0 & 86,0 & 7,9 & 700 & 8,04 \\
\hline 166 & 100,0 & 5,7 & 70,0 & 86,0 & - & 168 & 5,72 \\
\hline 288 & 100,0 & 13,8 & 70,0 & 86,0 & 0,5 & 299 & 7,90 \\
\hline 137 & 100,0 & 9,5 & 73,3 & 99,8 & - & 139 & 11,37 \\
\hline
\end{tabular}




\section{PESQUISA}

\section{ANEXO 1}

Distribuição da populaçâo, do número de óbitos e mortalidade proporcional por faixa etária, no total de óbitos e coeficiente geral de mortalidade e de alguns indicadores sócio-econômicos segundo zonas de informação - municipio de Salvador - Bahia - 1980

Óbitos por faixa etária (anos)

Zona de informação

No Nome

$$
\begin{array}{llllll}
\text { População } & 1 & 1-4 & 5-19 & 20-49 & 50
\end{array}
$$

No. MP No. MP No. MP No MP No MP

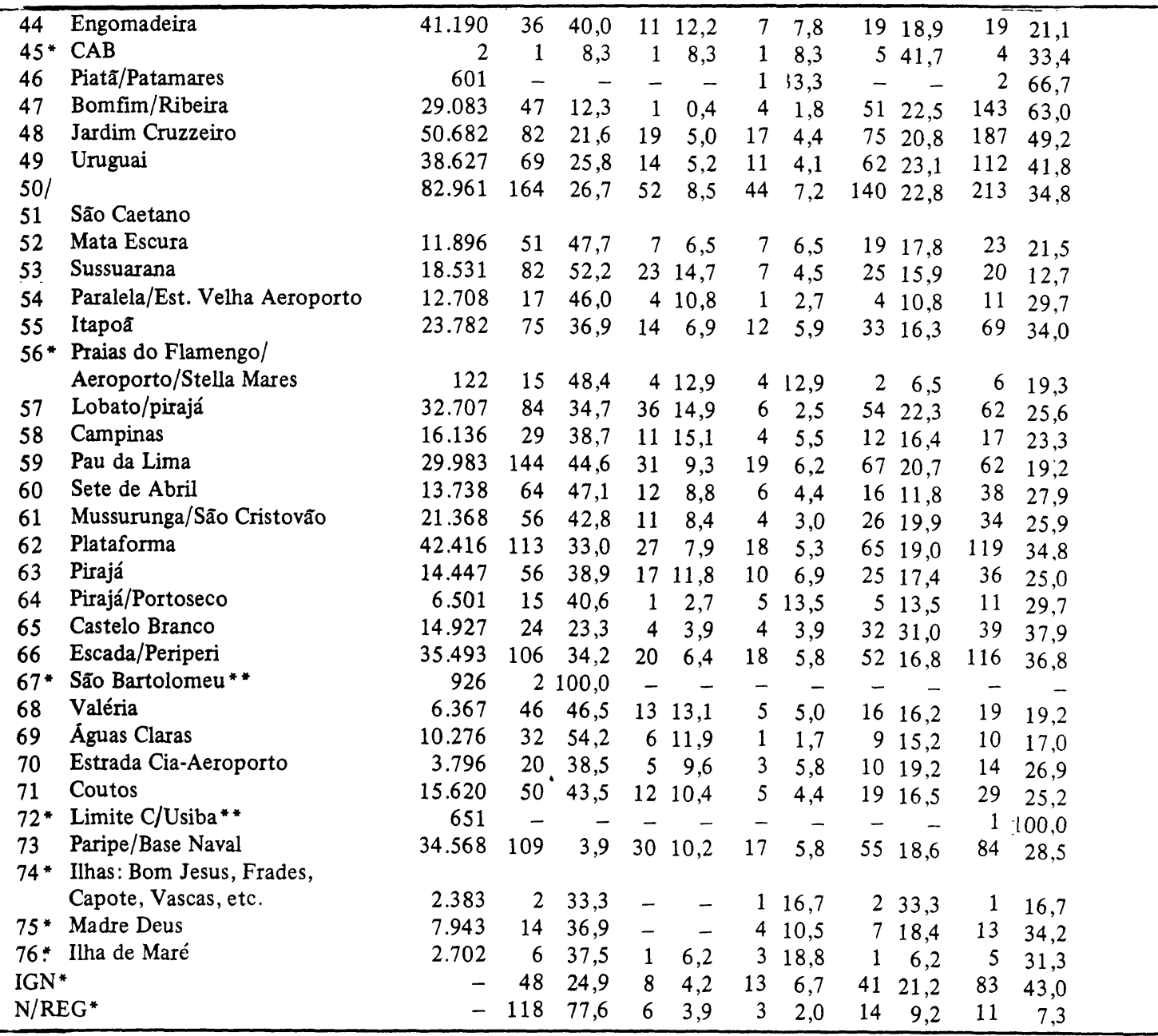

FONTE:

CIS (SESAB/ISEB); CONDER, EMBASA, SMS, 1? DIRES.

(1) incluindo os óbitos de idade ignorada

(2) coeficiente por 1.000 habitantes

* excluidos do estudo do Coeficiente Geral da Mortalidade

** excluidos do estudo da Mortalidade Proporcional. 


\begin{tabular}{|c|c|c|c|c|c|c|c|}
\hline \multicolumn{2}{|c|}{ Total $0-50$} & \multirow[t]{2}{*}{$\begin{array}{l}\mathrm{N}^{O} \text { de habitantes } \\
\text { por domicilio }\end{array}$} & \multirow{2}{*}{$\begin{array}{l}\text { Volume de água } \\
\text { (litros/dia) } \\
\text { consumido por } \\
\text { habitante/dia }\end{array}$} & \multirow{2}{*}{$\begin{array}{c}\text { Percentagem de } \\
\text { Habitantes com } \\
\text { renda na faixa } \\
\text { "C" }\end{array}$} & \multirow{2}{*}{$\begin{array}{c}\text { Nọ de médicos } \\
\text { de centros e } \\
\text { postos de saúde } \\
\text { por } 40.000 / \\
\text { habitantes } \\
\end{array}$} & \multirow{2}{*}{$\begin{array}{c}\text { Total } \\
\text { de } \\
\text { Obitos } \\
\text { No }\end{array}$} & \multirow[b]{2}{*}{$\begin{array}{c}(1) \\
\operatorname{CGM}(2)\end{array}$} \\
\hline No & MP & & & & & & \\
\hline 90 & 100,0 & 9,3 & 73,3 & 99,8 & - & 93 & 2,26 \\
\hline 12 & 100,0 & & $\therefore$ & & - & 12 & \\
\hline 3 & 100,0 & . & $\ldots$ & . & - & 3 & 4,99 \\
\hline 227 & 100,0 & 5,7 & 70,0 & 46,9 & - & 227 & 7,81 \\
\hline 380 & 100,0 & 8,9 & 70,0 & 46,9 & 2,4 & 392 & 7,73 \\
\hline 268 & 100,0 & 9,8 & 70,0 & 46,9 & - & 271 & 7,02 \\
\hline 613 & 100,0 & 9,5 & 70,0 & 86,0 & 1,6 & 616 & 7,43 \\
\hline 107 & 100,0 & 11,5 & 73,3 & 99,8 & - & 111 & 9,33 \\
\hline 157 & 100,0 & 10,7 & 73,3 & 92,0 & - & 167 & 9,01 \\
\hline 37 & 100,0 & 8,7 & 73,3 & 92,0 & - & 38 & 2,99 \\
\hline 203 & 100,0 & 5,9 & 73,3 & 87,1 & 10,1 & 206 & 8,66 \\
\hline 31 & 100,0 & & & & - & 32 & 262,30 \\
\hline 242 & 100,0 & 13,2 & 70,0 & 96,0 & - & 247 & 7,55 \\
\hline 73 & 100,0 & 11,0 & 43,3 & 96,0 & - & 76 & 4,71 \\
\hline 323 & 100,0 & 11,5 & 60,0 & 92,0 & 3,7 & 329 & 10,97 \\
\hline 136 & 100,0 & 10,0 & 60,0 & 92,0 & 9,5 & 139 & 10,12 \\
\hline 131 & 100,0 & 6,4 & 73,3 & 100,0 & 2,8 & 134 & 6,27 \\
\hline 342 & 100,0 & 8,4 & 43,3 & 94,2 & - & 346 & 8,16 \\
\hline 144 & 100,0 & 11,8 & 43,3 & 96,0 & 2,0 & 148 & 10,24 \\
\hline 37 & 100,0 & 11,8 & 60,0 & 96,0 & - & 40 & 6,15 \\
\hline 103 & 100,0 & 7,7 & 60,0 & 92,0 & 8,7 & 105 & 7,03 \\
\hline 310 & 100,0 & 6,8 & 66,7 & 94,2 & - & 314 & 8,84 \\
\hline 2 & 100,0 & $\ldots$ & & & - & 2 & 2,15 \\
\hline 99 & 100,0 & 7,4 & 43,3 & 94,2 & 1,6 & 102 & 16,02 \\
\hline 59 & 100,0 & 8,7 & 60,0 & 100,0 & - & 61 & 5,94 \\
\hline 52 & 100,0 & 6,9 & 73,3 & 100,0 & - & 56 & 14,75 \\
\hline 115 & 100,0 & 8,1 & 66,7 & 94,2 & - & 116 & 7,43 \\
\hline 1 & 100,0 & $\ldots$ & & $\ldots$ & - & 1 & 1,54 \\
\hline 295 & 100.0 & 6,7 & 66,7 & 94,2 & - & 302 & 8,74 \\
\hline 6 & 100,0 & & & & - & 6 & 2,5 \\
\hline 38 & 100,0 & & & & 13,8 & 39 & 4,9 \\
\hline 16 & 100,0 & & & & - & 16 & 5,92 \\
\hline 193 & 100,0 & - & - & - & - & 199 & - \\
\hline 152 & 100.0 & & & & & & \\
\hline
\end{tabular}


Assim, na tabela 1 verifica-se o CMG dos bairros que compuseram o 1 9 quartil com uma taxa média de 3,03 / 1000 variando de 0,96 na $\mathrm{ZI}$ correspondente ao $19 \mathrm{BC}$ a 5,51 no Canela. Observa-se nesse grupo certa heterogeneidade nos bairros que compreendem esse quartil como Parque de Nossa Senhora da Luz/Itaigara, Engomadeira, Jardim Apipema, Amaralina, Caixa D'Água, entre outros. A seguir, tem-se o 2 ? quartil com um coeficiente médio de 6,76/ 1000 com uma variação de 5,62 (Vitória/Campo Grande) a 7,43 (São Caetano). Tem-se aqui, também, uma composição heterogênea de bairros reunindo ondina, Mares, IAPI, Mussurunga, Barra, Uruguai, Castelo Branco, etc.

\section{TABELA 1}

Distribuição do coeficiente geral de mortalidade:

segundo as zonas de informação, nos quartis de "baixa", "intermediária", elevada" e "muito elevada" mortalidade

Município de Salvador - 1980

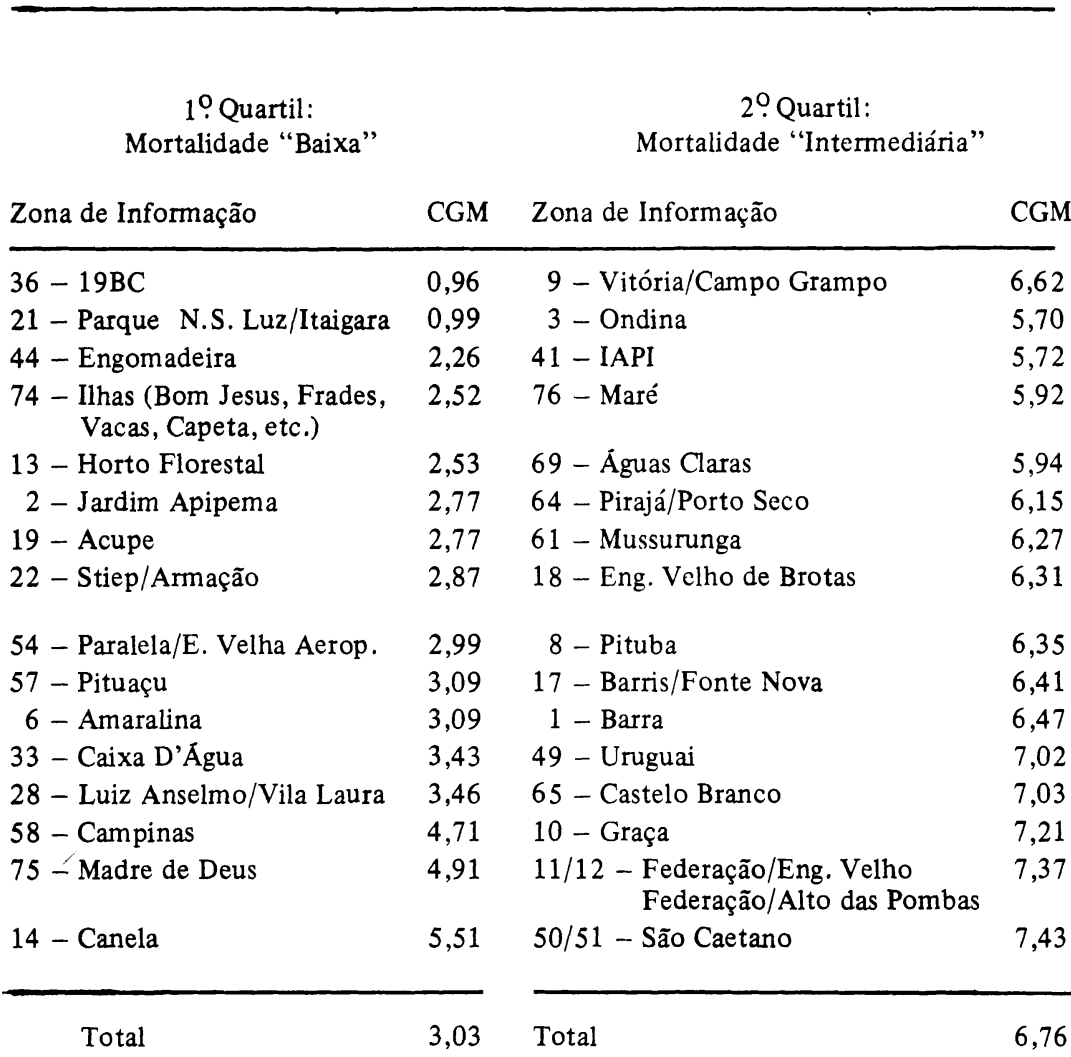


3‥ Quartil:

Mortalidade "Elevada"
4 ? Quartil:

Mortalidade "Muito Elevada"

\begin{tabular}{lclr}
\hline Zona de Informação & CGM & Zona de Informação & CGM \\
\hline 71 - Coutos & 7,43 & 31 - Boca do Rio & 9,48 \\
57 - Lobato/Pirajá & 7,55 & 26 - Matatu & 9,55 \\
7 - Nordeste de Amaralina & 7,56 & 32 - Barbalho/Lapinha & 9,78 \\
48 - Jardim Cruzeiro & 7,73 & $4 / 5$ - Rio Vermelho & 10,00 \\
& & & \\
16 - Garcia & 7,76 & 30 - Pernambués & 10,06 \\
47 - Bomfim/Ribeira & 7,81 & 60 - Sete de Abril & 10,12 \\
27 - Cosme de Farias & 7,89 & 63 - Pirajá & 10,24 \\
42 - Fazenda Grande Retiro & 7,90 & 24 - Pilar/Rua Chile/Baixa & 10,71 \\
& & dos Sapateiros & \\
$39 / 40$ - Liberdade & 8,04 & 25 - Nazaré/Saúde & 10,93 \\
62 - Plataforma & 8,16 & 59 - Pau da Lima & 10,97 \\
15 - Centro Histórico & 8,19 & 43 - São Gonçalo Retiro & 11,37 \\
34 - Quintas/Cidade Nova & 8,48 & 38 - Calçada/Mares/Roma & 11,43 \\
55 - Itapoã & 8,66 & 70 - Estrada CIA/Aeroporto & 14,75 \\
73 - Paripe/Base Naval & 8,74 & 20 - Brotas & 15,35 \\
66 - Escada/Periperi & 8,84 & 68 - Valéria & 16,02 \\
& & & \\
53 - Sussuarana & 9,01 & 23 - Frederico Pontes & 16,09 \\
52 - Mata Escura & 9,33 & 29 - Cabula & 18,92 \\
Total & 8,12 & Total & 11,50
\end{tabular}

FONTE: CIS - Declarações de Obito; CONDER

* Coeficiente por 100.000 hab.

Os coeficientes correspondentes ao 3 q quartil referem-se às ZI de elevada mortalidade geral. O CMG médio está em torno de 8,12, variando de 7,43 em Coutos a 9,33 em Mata Escura. Nessa tabela já se observam bairros com características mais semelhantes. Finalmente, constatam-se os coeficientes referentes ao 4 ? quartil com zonas de informações de "muito elevada" mortalidade geral, cujo valor médio é de $11,5 / 1000$ com uma variação de 9,48 (Boca do Rio) e 18,92 (Cabula). Destaca-se nesse quartil não só uma homogeneidade maior entre os bairros que eles compõem, mas especialmente as elevadas taxas nas ZI correspondentes a Brotas, Frederico Pontes, Valéria e Cabula.

Os bairros correspondentes aos quartis de baixa, intermediária, elevada e muito elevada mortalidade geral encontramse dispostos no mapa 1 .

$\mathrm{Na}$ tabela 2 e no mapa 2 encontram-se as zonas de informação correspondentes aos quartis de muito elevada, elevada, instermediária e baixa razão de mortalidade proporcional (RMP). O primeiro quartil tem uma RMP média de ¿adernos.de Saúde Públíca, R.J., 2 (3) : 312-333, jul/set, 1986. 
$62,6 \%$ com uma variação de $76,6 \%$ (Canela) e 52,5 (Engenho Velho de Brotas). Notam-se, nessa lista, bairros com melhores condições sócio-econômicas como Canela, Graça, Campo Grande/Vitória, Barra, Pituba, etc. No segundo quartil (zona de elevada RMP) ocorre uma variação a de $52,1 \%$ (Horto Florestal) a $36,8 \%$ (Escada/Periperi) tendo um valor médio de $47,3 \%$. Verifica-se uma maior diversidade de bairros incluídos nesse quartil, tais como Liberdade, Brotas, Jardim Cruzeiro, Uruguai, Nordeste, Castelo Branco, Escada, Periperi, etc. O terceiro quartil, com zonas de intermediária RMP e tendo como valor médio $32,7 \%$, mostra uma variação de $36,3 \%$ (Parque Nossa Senhora da Luz/Itaigara) a $26,9 \%$ (Estrada CIA/Aeroporto). Com a exceção do Parque Nossa Senhora da Luz/Itaigara, todas as demais ZI apresentam características sócio-econômicas semelhantes. O quarto quartil (zonas de baixa RMP) tem uma RMP média em torno de $22,4 \%$ variando de $25,9 \%$ (Mussurunga/São Cristóvão) a 12,7\% (Sussuarana). Verificase certa homogeneidade nas zonas de informação que compõem este quartil, representando o "miolo" da Cidade de Salvador, a periferia e parte do subúrbio ferroviário.

\section{MAPA 1}

Distribuição do Coeficiente Geral de Mortalidade, Segundo as Zonas de Informação Município de Salvador - 1980

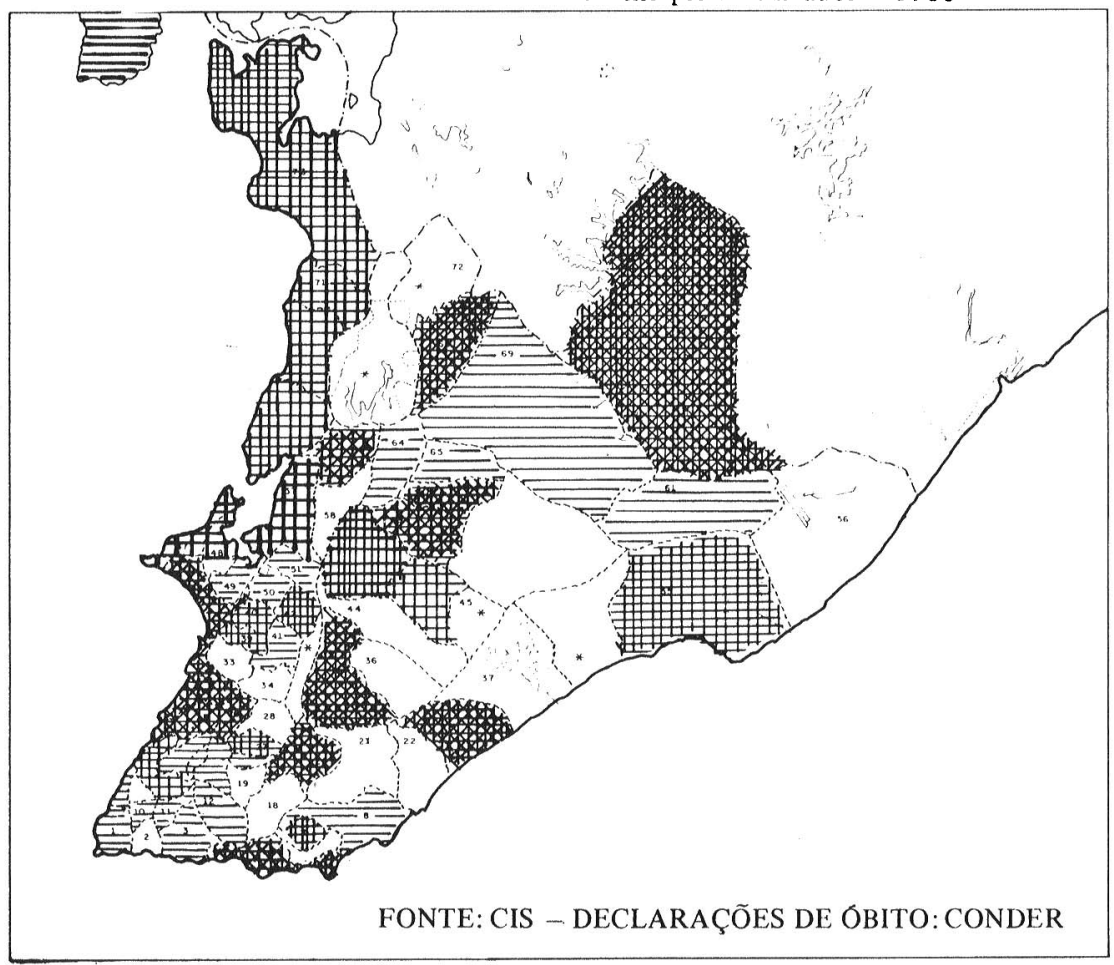

LICIINDA: $0,96 \% \AA 5,51 \%$ $\rightleftharpoons 5,62 \% \AA 7,43 \%$ 舟册 7,43\% 9 9,33\% $9,48 \%$ A $18,92 \%$ 
MAPA 2

Distribuição da Mortalidade de 50 anos e mais, Segundo as Zonas de Informação Município de Salvador - 1980

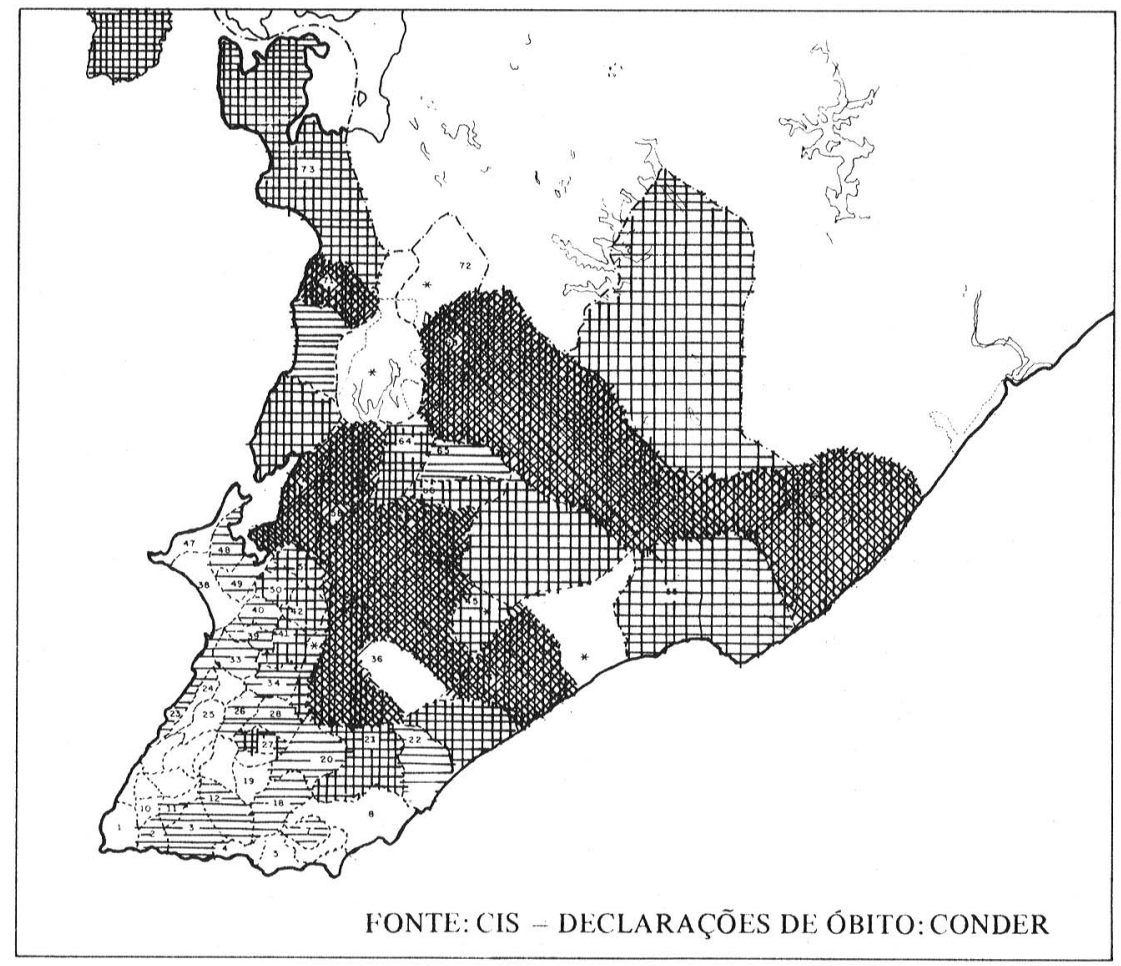

\section{LEGENDA :} $76,6 \% \AA$

$5,21 \% \AA 36,8 \%$

\section{TABELA 2}

Distribuição da mortalidade proporcional de 50 anos e mais, segundo as zonas de informação, nos quartis de "muito elevada", elevada": "intermedidria" e "baixa" razão de mortalidade proporcional (RMP) - Municipio de Salvador - 1980

\begin{tabular}{|c|c|c|c|}
\hline $\begin{array}{l}\text { 19 Quartil: } \\
\text { "Muito Elevada RMP" }\end{array}$ & & $\begin{array}{l}2{ }^{\circ} \text { Quartil: } \\
\text { "Elevada RMP" }\end{array}$ & \\
\hline Zona de Informação & RMP & Zona de Informação & RMP \\
\hline 14 - Canela & 76,6 & 13 - Horto Florestal & 52,1 \\
\hline 16 - Garcia & 72,7 & $39 / 40$ - Liberdade & 52,0 \\
\hline 10 - Graça & 72,1 & $20-$ Brotas & 51,8 \\
\hline 38 - Calçada/Mares/Roma & 69,8 & 34 - Quintas/Cidade Nova & 51,3 \\
\hline 26 - Matatu & 68,7 & $\begin{array}{l}11 / 12 \text { - Federação/Eng. Velho } \\
\text { Federação/Alto das Pombas }\end{array}$ & 50,0 \\
\hline 25 - Nazaré/Saúde & 67,8 & 28 - Luiz Anselmo/Vila Laura & 50,0 \\
\hline 9 - Campo Grande/Vitória & 66,7 . & 48 - Jardim Cruzeiro & 49,2 \\
\hline 1 - Barra & 64,8 & 32 - Barbalho/Lapinha & 49,1 \\
\hline 33 - Caixa D'água & 63,7 & 3 - Ondina & 48,4 \\
\hline 47 - Boñfim/Ribeira & 63,0 & 2 - Jardim Apipema & 47,2 \\
\hline
\end{tabular}

Cadernos de Saúde Pública, R.J., 2 (3): 312-333, jul/set, 1986. 


\begin{tabular}{|c|c|c|c|}
\hline Zona de Informação & RMP & Zona de Informação & RMP \\
\hline 17 - Barris & 57,0 & 4/5 - Rio Vermelho & 47,0 \\
\hline 8 - Pituba & 56,9 & 49 - Uruguai & 41,8 \\
\hline 6 - Amaralina & 56,8 & 23 - Frederico Pontes & 38,7 \\
\hline $\begin{aligned} 24 \text { - } & \text { Pilar/Rua Chile/Baixa } \\
& \text { dos Sapateiros }\end{aligned}$ & 55,2 & 22 - Stiep/Armação & 38,5 \\
\hline 9 - Acupe & 53,5 & 7 - Nordeste de Amaralina & 38,1 \\
\hline 5 - Centro Histórico & 53,4 & 65 - Castelo Branco & 37,9 \\
\hline 8 - Eng. Velho de Brotas & 52,5 & 66 - Escada/Periperi & 36,8 \\
\hline Total & 62,6 & Total & 47,3 \\
\hline
\end{tabular}

\begin{tabular}{|c|c|c|c|}
\hline $\begin{array}{c}\text { 3\%. Quartil: } \\
\text { "Intermediária RMP" }\end{array}$ & & $\begin{array}{l}\text { 4\% Quartil: } \\
\text { "Baixa RMP" }\end{array}$ & \\
\hline 21 - Itaigara/Parque N.S. Luz & 36,3 & 61 - Mussurunga/São Cristovão & 25,9 \\
\hline 27 - Cosme de Farias & 35,2 & 57 - Lobato/Pirajá & 25,6 \\
\hline 62 - Plataforma & 34,8 & 29 - Cabula & 25,3 \\
\hline 50/51 - São Caetano & 34,8 & 71 - Coutos & 25,2 \\
\hline 42 - Fazenda Grande Retiro & 34,4 & 63 - Pirajá & 25,0 \\
\hline 75 - Madre de Deus & 34,2 & 43 - São Gonçalo Retiro & 24,8 \\
\hline 55 - Itapoá & 34,0 & 37 - Pituaçu & 23,8 \\
\hline 35 - Acesso Norte & 33,4 & 58 - Campinas & 23,3 \\
\hline $45-\mathrm{CAB}$ & 33,4 & 30 - Pernambués & 23,0 \\
\hline 76 - Maré & 31,3 & 52 - Mata Escura & 21,5 \\
\hline 31 - Boca do Rio & 31,2 & 44 - Engomadeira & 21,1 \\
\hline 54 - Paralela/Est. Velha Acr. & 29,7 & $\begin{array}{l}56 \text { - Praias do Flamengo/ } \\
\text { Stela Mares/Aeroporto }\end{array}$ & 19,3 \\
\hline 64 - Pirajá/Portoseco & 29,7 & 59 - Pau da Lima & 19,2 \\
\hline 41 - IAPI & 29,0 & 68 - Valéria & 19,2 \\
\hline 73 - Paripe & 28,5 & 69 - Águas Claras & 17,0 \\
\hline 60 - Sete de Abril & 27,9 & 53 - Sussuarana & 12,7 \\
\hline 70 - Estrada CIA/Acroporto & 26,9 & & \\
\hline Total & 32,7 & Total & 22,4 \\
\hline
\end{tabular}

Nos gráficos 2, 3, 4, e 5 tem-se a representação desses quartis através da curva de mortalidade proporcional. Assim o gráfico 2 sugere um nível sanitário "elevado". Os gráficos 3 e 4 apresentam curvas que indicam um nível de saúde "regular" enquanto o gráfico 5, correspondente ao último quartil, dispõe de uma curva sugestiva de "baixo" nível de saúde.

Quando foi aplicado o sistema de pontuação proposto por Guedes e Guedes ${ }^{4}$ para cada grupo de zonas (Tabela 3 ; Cadernos de Saúde Rública, R.J., 2 (3): 312-333, jul/set, 1986. 
percebem-se coeficientes bastante expressivos (variando de $+19,7$ a $-14,2$ ) ficando patente a diferença entre os mesmos. Quando esse procedimento foi aplicado aos dados globais de Salvador, o coeficiente foi apenas de $+1,77$.

GRĀFICOS 2 A 5

MORTALIDADE PROPORCIONAL, SEGUNDO FAIXA ETÅRIA NOS GRUPOS DE ZONAS DE INFORMAÇÃO DE MUITO ELEVADA, ELEVADA, INTERMEDIÁRIA E BAIXA RAZĀO DE MORTALIDADE PROPORCIONAL,MUNICÍPIO DE SALVADOR - 1980 $\%$

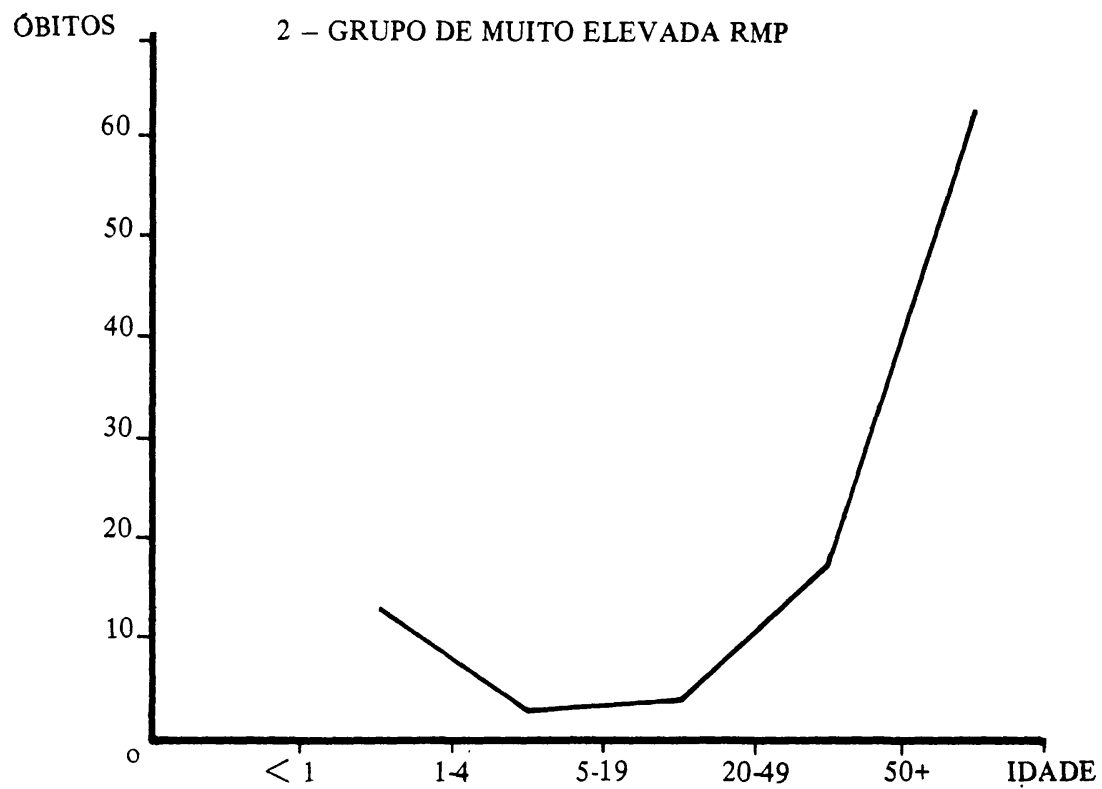

$\%$

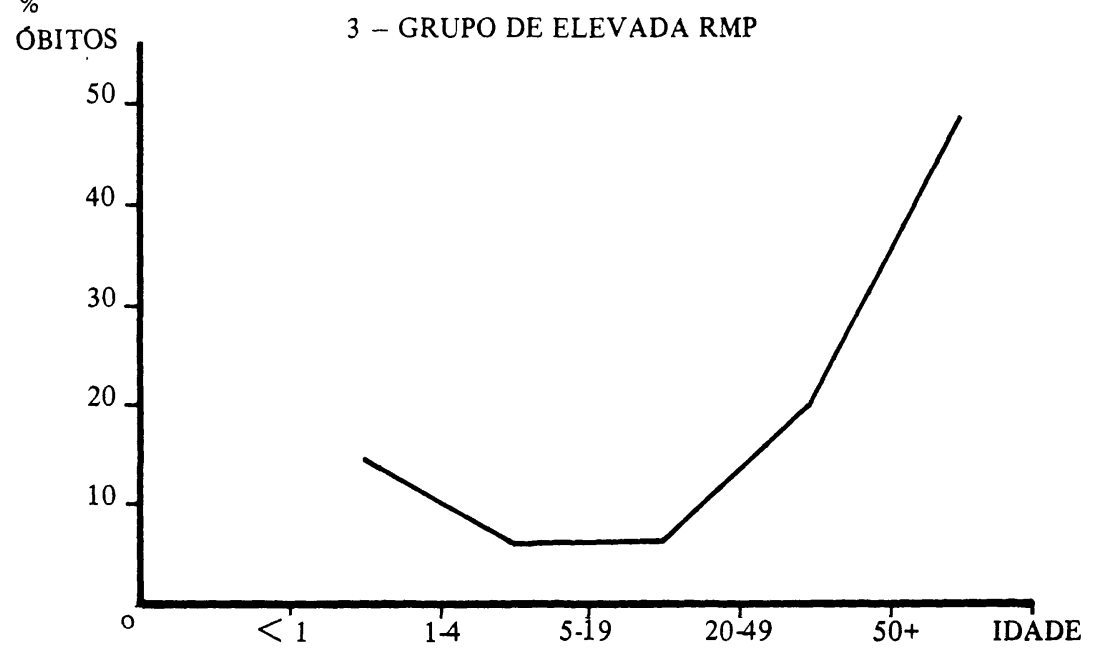

Cadernos de Saúde Pública, R.J., 2 (3): 312-333, jul/set, 1986. 
PESQUISA

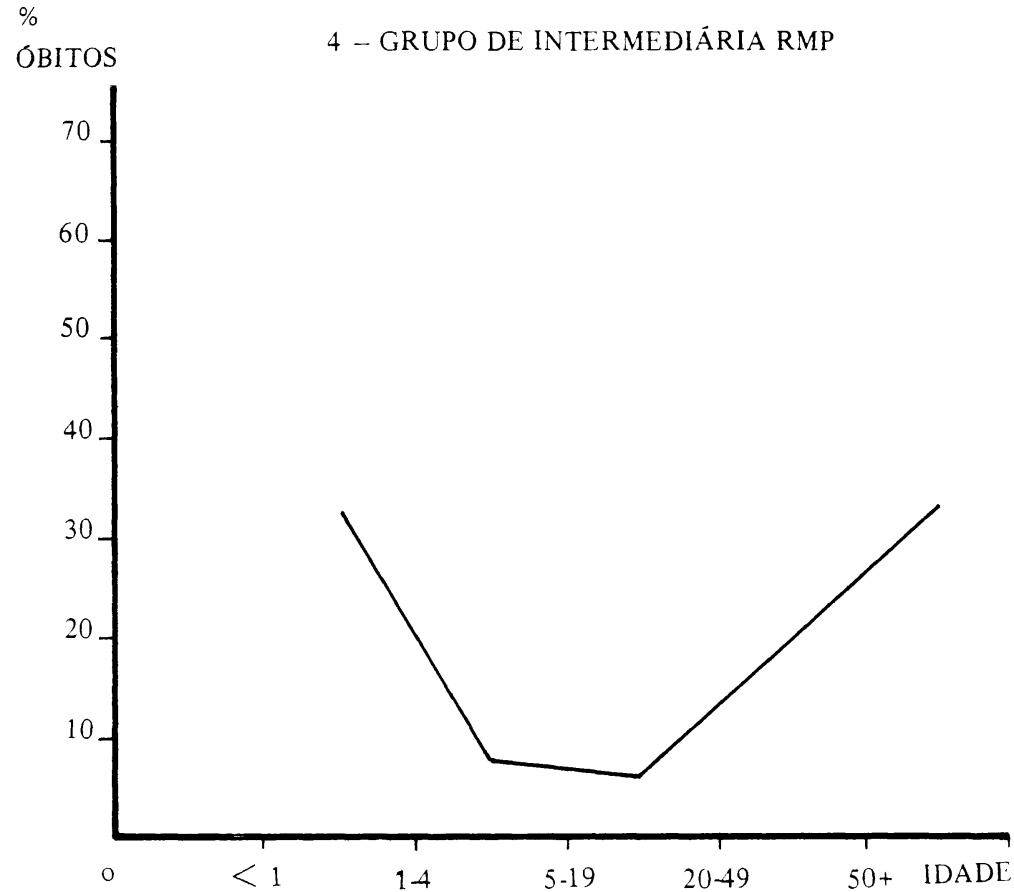

$\%$

OBITOS 5 - GRUPO DE BAIXA RMP

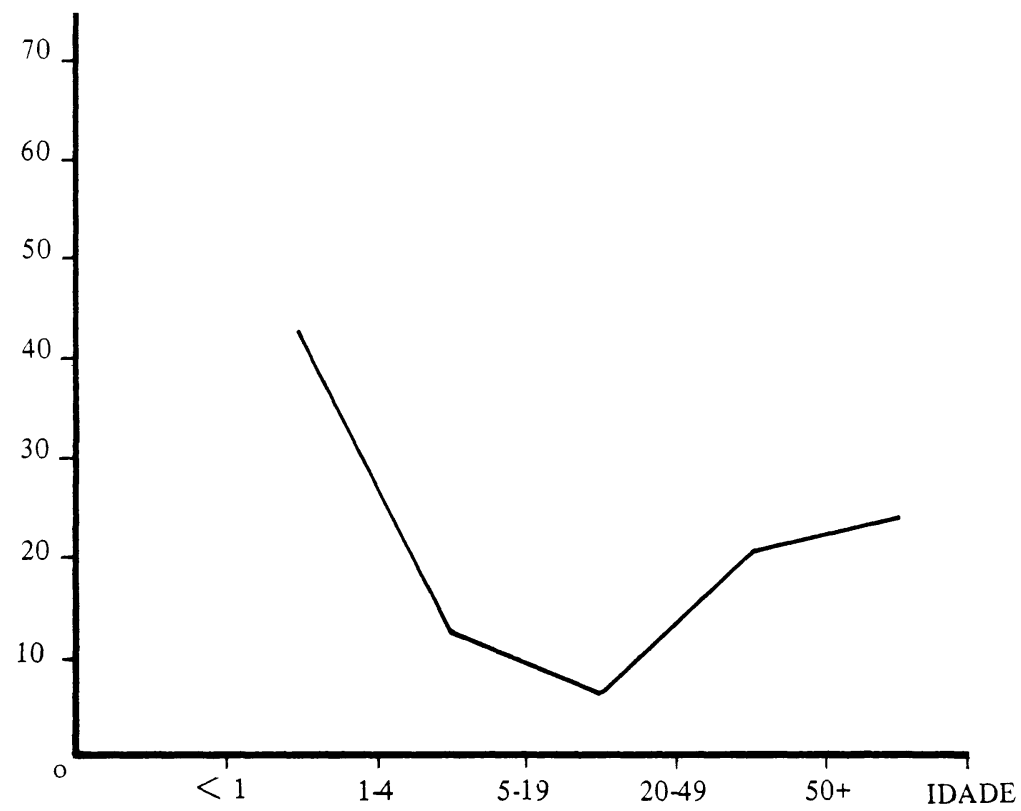

Fonte: SESAB/CIS 


\section{TABELA 3}

Mortalidade porporcional e indicador de Guedes e Guedes, segundo faixa etária e grupos de zonas de informação de acordo com a razão de mortalidade proporcional Municipio de Salvador - 1980

\begin{tabular}{rrrrrrrrrrr}
\hline $\begin{array}{r}\text { Faixad } \\
\text { Etária }\end{array}$ & $\begin{array}{c}\text { Grupos de ZI } \\
\text { Segundo } \\
\text { RMP }\end{array}$ & \multicolumn{2}{c}{$\begin{array}{c}\text { Muito } \\
\text { Elevada }\end{array}$} & \multicolumn{2}{c}{ Elevada } & \multicolumn{2}{c}{ Intermediária } & & \multicolumn{2}{c}{ Baixa } \\
& & MP & G \& G & MP & G \& G & MP & G \& G & MP & G \& G \\
\hline & $<1$ & 13,5 & $(-54,0)$ & 24,1 & $(-96,4)$ & 32,7 & $(-130,8)$ & 42,2 & $(-168,8)$ \\
1 & 4 & 2,6 & $(-5,2)$ & 5,1 & $(-10,2)$ & 8,4 & $(-16,8)$ & 11,5 & $(-23,0)$ \\
5 & 19 & 3,6 & $(-3,6)$ & 4,9 & $(-4,9)$ & 6,4 & $(-6,4)$ & 4,7 & $(-4,7)$ \\
20 & 49 & 17,7 & $(-52,8)$ & 18,6 & $(-55,8)$ & 19,8 & $(-59,4)$ & 19,2 & $(-57,6)$ \\
$50+$ & & 62,6 & $(+313,0)$ & 47,3 & $(+236,5)$ & 32,7 & $(+163,5)$ & 22,4 & $(+112,0)$ \\
\hline TOTAL & & 100,0 & $(+19,7)$ & 100,0 & $(+6,9)$ & 100,0 & $(-7,9)$ & 100,0 & $(-14,2)$
\end{tabular}

Fonte: $\mathrm{SASAB} / \mathrm{CIS}$

$G \& G \times$ Guedes e Guedes

Com referência aos coeficientes de correlação e os níveis de significância resultantes da relação entre a mortalidade proporcional de 50 anos e mais, e as variáveis independentes selecionadas para o conjunto de 62 zonas de informação de Salvador (Tabela 4), verificou-se uma evidente relação negativa entre a RMP e percentual de familias com baixa renda $(r=-0,68)$ da mesma forma que a aglomeração $(\mathrm{r}=-0,61)$. Quanto à disponibilidade de água, observa-se uma relação inversa $(+0,62)$. A relação da RMP com estes três indicadores mostrou-se estatisticamente significante ao nível de 0,001 , o que não ocorreu com a relação com o número de médicos de Centros e Postos de Saúde que apre. sentou um $r=0,22$, não sendo estatisticamente significante ao nível de $5 \%$.

\section{TABELA 4}

Coeficientes de correlação entre a mortalidade proporcional de 50 anos e mais e as variáveis independentes selecionadas para 62 zonas de informação - Município de Salvador, 1980

\begin{tabular}{lc}
\hline $\begin{array}{c}\text { Variáveis } \\
\text { Independentes }\end{array}$ & $\begin{array}{c}\text { Coeficientes de } \\
\text { Correlação }\end{array}$ \\
\hline RI:NDA & $-0,68^{*}$ \\
RLNDA DISPONIBILIDADE DF ÁGUA & $0,62^{*}$ \\
DISPONIBILIDADE AGLOMI:RAÇĀO & $-0,61^{*}$ \\
MEDICOS DE C.S. e P.S. POR 10.000/hab. & $0,22^{* *}$ \\
& \\
${ }^{*} \mathrm{p}<0,001$ & \\
${ }^{*} \mathrm{p}>0,05$ &
\end{tabular}

Cadernos de Saúde Pública, R.J., 2 (3): 312-333, jul/set, 1986. 


\section{DISCUSSÃO}

O estudo da distribuição espacial da totalidade de óbitos ocorridos em Salvador no ano de 1980 revela uma variação expressiva dos indicadores entre os diferentes bairros da cidade. $\mathrm{O}$ recurso à utilização de indicadores de saúde de características diversas como o coeficiente de mortalidade geral, o índice de Swaroop-Uemura, o indicador de Moraes e o Sistema de pontuação de Guedes e Guedes permitiu ressaltar os distintos níveis de saúde observados para uma população residente numa mesma cidade. Enquanto indicadores globais de saúde, apontam para as condições de saúde do conjunto da população e não apenas para aqueles segmentos etários mais susceptíveis aos riscos do ambiente, como é o caso dos estudos sobre mortalidade na infância ${ }^{3}$.

No que diz respeito ao comportamento do coeficiente de mortalidade geral nas diferentes zonas de informação, cabe destacar a acentuada variação de 0,96 óbitos por 1000 habitantes no caso do $19 \mathrm{BC}$ a 18,92 no Cabula. Esses dados são, todavia, interessantes para sugerir a existência de problemas na classificação dos óbitos segundo o bairro de residência. Embora as ZI correspondentes ao $19 \mathrm{BC}$ e ao Cabula sejam contíguas e apresentem condições ambientais e sócio-ecônômicas semelhantes, verifica-se grande diferença. Assim, é possivel admitir uma tendenciosidade da Declaraçao de Óbito com relação. ao item 13 correspondente ao bairro de modo a registrar mais o Cabula por ser mais conhecido que o $19 B C$.

Outra limitação digna de registro diz respeito à influência da estrutura etária da população sobre o coeficiente de mortalidade geral, quando as taxas não são padronizadas. É o caso de um bairro como o Matatu, que se encontra no quartil correspondente às zonas de mortalidade geral "muito elevada" quando, na realidade, apresenta uma baixa proporção de óbitos de menores de 1 ano e uma alta proporção de óbitos no grupo etário de 50 anos e mais $(68,7 \%)$. Desse modo, é possível que a estrutura etária dessa população composta da maior proporção de pessoas adultas e idosas apresente naturalmente uma mortalidade maior. Esta é uma das explicações possiveis para a grande heterogeneidade verificada entre os bairros agrupados nos diferentes quartis em função do CMG. Estariam sendo reunidas num mesmo quar. til ZI com baixo CMG porque a estrutura etária é jovem, embora de baixo nível sócioeconômico ou porque o padrão de vida é alto, apesar de dispor de uma população com idade mais avançada. Conseqüentemente, o CMG apesar de demonstrar diferença entre os bairros, não discriminou bem as zonas integrantes dos três primeiros quartis. 
Só mesmo o quartil correspondente as ZI de "muito elevada" mortalidade geral apresenta maior homogeneidade na sua composição tendo 13 bairros com CMG superior a 10 óbitos/mil habitantes.

Quanto à razão da mortalidade proporcional (RMP) ou índice de Swaroop-Uemura, percebe-se especialmente através do mapa 2 a grande variação entre as diferentes zonas da cidade. Considerando-se que uma proporção maior de óbitos na faixa etária de 50 anos e mais indica que a população já não morre tanto na idade jovem e, portanto, tende a apresentar melhores condiçoes de saúde, cabe destacar como esse índice vai decrescendo dos bairros centrais para a periferia e o subúrbio ferroviário, alcançando valores inferiores a $25,9 \%$ nos bairros de recente assentamento populacional denominado "miolo" da cidade de Salvador. Essa área abriga diferentes invasões e favelas que acompanham o crescimento urbano do Município. Embora esse indicador não expresse a idéia de risco, mostrou-se com grande capacidade de discriminação para as diferentes $\mathrm{ZI}$. Na medida em que ele foi empregado para a definiçáo dos quartis, foram obtidas curvas de mortalidade proporcional (índice de Moraes) bastante ilustrativas dos distintos subconjuntos de bairros. Assim houve bairros com nível sanitário "elevado" compatível com regiões desenvolvidas, vários com nível "regular" e outros com "baixo" nível sanitário, característico das regiões subdesenvolvidas. Tal variação ficou evidente ao se utilizar o sistema de pontuação de Guedes e Guedes para esses quartis. Quando o mesmo foi aplicado aos dados globais de Salvador, no entanto, verifica-se um baixo nível de discriminação.

Tais resultados, por sua vez, reforçam a idéia básica desta investigação de que os indicadores de saúde de caráter global divulgados pelos organismos oficiais não expressam a diversidade das condições de saúde entre os diferentes seg. mentos da população, por não considerar a influência da estrutura econômica na sua determinação. A relevância deste fator mais uma vez fica evidenciada, pelo encontro da forte correlação entre a "Razão da Mortalidade Proporcional" e a percentagem de população de baixa renda, da mesma forma que já verificada em estudo anterior com relação a mortalidade infantil proporcional, apesar de ño estar se tratando de um indicador tão sensivel quanto a este. Se aquelas informações apresentam importância estatística na construção de séries históricas, ou na comparação interregional, são limitantes, para uma política social que privilegie a eqüidade e a eficácia das ações de saúde. 
The present study is aimed to describe the mortality in the county of Salvador in 1980, as distributed over different areas, by using overall mortality coefficients, proportional mortality ratios, proportional mortality curves and Guedes \& Guedes indicators. Death certificates from residents in Salvador during 1980, available in the Health State Office of Bahia, were used as data sources. They were grouped according to census tracts as defined by CONDER (Company for the Development of Salvador) as well as socio-economic indicators gathered from several sources in different public offices. Correlation analyses between mortality measures and selected socio-economic indicators were used. A marked variation of indicators among different city sectors was found, even considering the use of an indicator with low discriminant power as the overall mortality coefficient. The indexes of Moraes and Swaroop-Uemura and Guedes \& Guedes scoring system pointed out evident inequalities in the distribution of deaths among different sectors of Salvador. High levels of correlation were found between proportional mortality ratio and income, water supply, and population density, reinforcing the idea that at the basis of such mal-distribution is the economic structure as a generator of inequalities.

\section{REFERENCIAS BIBLIOGRAFICAS}

1. ANUÁRIO ESTATÍSTICO DO BRASIL. Rio de Janeiro, v. 41, 1980.

2. BAHIA. Companhia de Desenvolvimento da Região Metropolitana. Base cadastral da região metropolitana de Salvador. Salvador, 1981.v. 1.

3. COSTA, M.C.N.; PAIM, J.S.; CABRALL, V.M.C. \& MOTA, J.A. Mortalidade em crianças de 1-4 anos. Salvador, 1980. R. haiana Saúde públ., 12 (1/3): 15-28, 1985.

4. GUEDES, J. da S. \& GULDES, M.L. da S. Quantifícação do indicador de Nelson de Moraes (Curva de Mortalidade Proporcional) $R$. Saúde públ., 7: 103-13, 1973.

5. JORDAN FILHO, L.; MONTLIRO, M.F.(;. \& CARVALHO, A.V.W. de. Revisão analítica dos indicadores de saúde. $R$. bras. Estat, 35 (139): 339-56, 1974.

6. LAURENTI, R. A medida das doenças. In: FORATTINI, O.P. Epidemiologia geral. São Paulo, Artes Médicas, 1980. p. 64-85.

7. MAcMAHON, B.; PUGH, T.I. \& IPSLN, J. Métodos de epidemiologia. México, La Prensa Medica Mexicana; São Paulo, Blucher, 1976. p. 121-22.

8. MORAES, N.L. de A. Níveis de saúde de coletividades brasileiras. R. Saúde públ., 10: 403-97, 1957.

9. NOVO, N.F.; JULIANO. Y.; PAIVA, E.R. de \& LESER, W. Ordenação de populações em amplas classes de níveis de 
saúde, segundo um indicador abrangente definido por uma função discriminante linear. $R$. Saúde publ., 19: 344-63, 1985.

10. OLIVEIRA, F. Salvador: os exilados da opulência (expansão capitalista numa metrópole pobre). In: SOUZA, C.A.A. de \& FARIA, V. Bahia de todos os pobres. Petrópolis. Vozes/ CEBRAP, 1980. p. 9-21.

11. PAIM, J. S. Indicadores de saúde no Brasil. $R$. baiana Saude púlb. 2 (2): 39-83, 1975.

12. PAIM, J.S.; COSTA, M.C.N.; CABRAL, V.M.C. \& MOTA, I.A. Distribuição espacial de mortalidade infantil porporcional e sua relação com variáveis sócio-econômicas, Salvador-BA. (Brasil). (No prelo).

13. ROUQUAYROL, M.Z. Epidemiologia e saúde. Fortaleza, UNIFOR, 1983, p. 15-52.

14. SIMÕES, M.L. Invasões: agentes da produção da cidade do Salvador. Cad. CEAS, 99:3643, 1985.

15. SWAROOP, S. \& UEMURA, K. Proportional mortality of 50 years and above: a suggested indicator of the component "health including demographic conditions" in the measurement of living. Bull. WHO, 17: 439-81, 1957. 